\title{
DYNAMIC MECHANICAL ANALYSIS OF HYBRID COMPOSITES OF DISCARDED FISHNET AND GLASS FIBRE REINFORCEMENT WITH POLYESTER MATRIX
}

\author{
${ }^{*}$ Michael Raj F $F^{1}$, Sahaya Elsi $S^{2}$, Emina MS $^{2}$ Freeda $S^{3}$, Amala Midun Minther Singh $\mathrm{A}^{4}$ and \\ Jayaram $\mathbf{R S}^{5}$
}

\begin{abstract}
${ }^{1}$ Department of Mechanical Engineering, Stella Mary's College of Engineering, Aruthenganvilai, Tamil Nadu-629202, India ${ }^{2}$ Department of Electronics and Electrical Engineering, University College of Engineering Nagercoil, Tamil Nadu-629004, India ${ }^{3}$ Department of Electronics and Electrical Engineering, Udaya School of Engineering, Vellamodi, Tamil Nadu- 629204, India. ${ }^{4}$ Department of Mechanical Engineering, DMI College of Engineering, Chennai, Tamil Nadu- 600123, India.

${ }^{5}$ Department of Mechanical Engineering, Amrita College of Engineering and Technology, Nagercoil, Tamil Nadu-629901, India
\end{abstract}

\begin{abstract}
Polyester based composites were fabricated and characterized for their tensile,morphological and dynamic mechanical properties such as storage and loss moduli as a function of temperature. The morphological attributes were characterized by scanning electron microscopy (SEM) and COSLAB microscope. The morphological investigations have revealed a uniformly distributed polyester matrix of the composites. Dynamic mechanical analysis (DMA) revealed an enhancement in the energy dissipation ability of the composite $4 \mathrm{GF}$ and an average storage modulus of the composite $3 \mathrm{GF} / 1 \mathrm{FN}$ relative to the soft polyester phase. The tensile modulus and tensile strength increased up to $0.5 \%$, accompanied by while the strain at break remained largely unaffected. Fractured surface morphology indicates that the failure mode of the composites undergoes a switch-over from matrix-controlled shear deformation to the filler-controlled loading of the composites for specific applications. Hence, the utilization of discarded fishnet incorporatedcomposites mitigates the problem of waste disposal.
\end{abstract}

Keywords: Hybrid composites, Strength, Elastic properties, Dynamic mechanical thermal analysis, Scanning electron microscopy.

\section{Introduction}

Fibre-reinforced polymer composites made up of glass and other synthetic fibres give the advantages such as their adequate specific properties, low cost, good biodegradability, low density and high aspect ratio for efficient stress transfer [1]. Reinforcing single fibre composites can be replaced with several fibres, which incorporate into a matrix and lead to the development of hybrid composites in which the properties of the composites are the combination of properties of individual fibres.

Hybridization of natural/synthetic fibres helps to utilise some inherent and adequate properties of the individual fibre to enhance the properties of the composites [2]. The properties of the composite depend on the properties of the fibre, properties of the matrix, interfacial adhesion between the fibre and matrix, and the hybrid system design [3]. The addition of glass fibres in small amounts to the sisal and pineapple fibre polyester hybrid composites increased the mechanical properties of the composites [4]. Athijayamani et al. [5] performed an experiment on Roselle/sisal-polyester composites, and their results shows that varying sisal fibre content in Roselle/sisal polyester composites resulted in enhanced properties of the composites.

The viscoelastic behaviour of polymeric materials for determining composite stiffness and damping behaviour for various applications can be found using dynamic mechanical analysis.

The main objectives of dynamic mechanical analysis are to study the modification of the matrix due to the incorporation of the fibre and the behaviour of the composites [6]. Almeida Junior et al. [7] investigated the dynamic mechanical performance of curaua/glass hybrid composites with varied fibre contents and reported that incorporation of glass fibres increased the storage modulus of the composites but didn't have any influence on the glass transition temperature $(\mathrm{Tg})$. Idicula et al. [8] studied the static and dynamic mechanical performance of randomly oriented intimately mixed short banana/sisal polyester hybrid composites to better mechanical performance depending on the fibre volume. 
Jute fibres were hybridized with oil palm fibres in an epoxy matrix. As a result of hybridization an improvement in static and dynamic properties of composites was observed due to the enhanced fibre matrix adhesion [10]. Ozturk [11] evaluated the mechanical properties of jute/rock wool reinforced phenol formaldehyde hybrid composites and found that the amount of fibre in the composites influences the properties of the composites. Gu et al. [12] studied the damping properties of fly ash filled with epoxy composites where the slow attenuation of loss-tangent with increasing frequency has been reported and indicates better damping characteristics. The dynamic mechanical analysis of natural fibre based hybrid composites was performed and observed that the hybridization of natural fibre improved thermal and dynamic mechanical properties [13]. Glass/banana hybrid polyester composites are subjected to dynamic mechanical analysis over a range of temperatures and three different frequencies [14]. Similar work on mechanical and dynamic mechanical properties of sisal/glass hybrid composites resulted in an increase in storage and loss modulus with hybridization of sisal/polyester with glass fibres [15]. The discarded fishnet fibres can be improved by adding hybrid laminates conversely higher mechanical properties [1622].

The composites exhibited an increase in properties to certain fibre loading levels and then decreased further addition of fibres. So an optimum ratio of fibre to the matrix is very much essential to achieve improved properties.

This paper reveals the tensile and dynamic mechanical behaviour of discarded multifilament fishnet fibre of mesh size $32 \mathrm{~mm}$ and glass fibre with polyester hybrid composites. The bi-layer arrangement of fibres is used in the design of the hybrid system. Composite specimens were prepared with glass fibre layers and fishnet layers at five different combinations. The
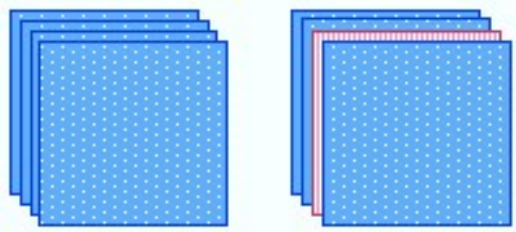

(A)

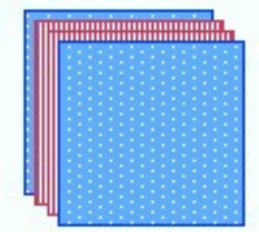

(B)
(C) properties of the present hybrid composites are compared with the properties of glass fibre composites.

\section{Experimental Methods}

\subsection{Materials}

The discarded multifilament fishnet (gill nets), of mesh size $32 \mathrm{~mm}$ was collected from thecoastal area in Kanyakumari district, Tamil Nadu, India. The twine diameter of the discarded fishnet is $0.27 \mathrm{~mm}$, single knotting, white in colour and stretched orientation. A glass fibre grade of $300 \mathrm{~g} / \mathrm{m}^{2}$ was obtained from Binani India products, Chennai. Unsaturated polyester grade of SBA2303-Isothalic. Methyl Ethyl Ketone Peroxide (MEKP) at a concentration of $0.01 \mathrm{w} / \mathrm{w}$ was used as the catalyst and Cobalt Naphthenate as an accelerator; all these AR grade chemicals were obtained from the Ciba Gugye Limited, Chennai, India. The specific properties of the fabricated materials are listed in Table 1.

\subsection{Preparation of Hybrid Composites}

The collected fishnet was washed three times with water $(\mathrm{pH}$ value 7.00$)$ at room temperature $\left(30 \pm 2{ }^{\circ} \mathrm{C}\right)$ and dried through direct sunlight for 1 hour for removing the sodium chloride and dirt. The specimens were fabricated by the hand lay-up method. Fishnet layer was obtained by spreading the fishnet at stretched orientation; glass fibre layers were obtained by spreading the mat. Polyester matrix was coated on these glass fibres and fishnet reinforcement layers. The polyester resin applied was distributed to the entire surface using a brush and roller. The processed composite was pressed with a roller, and the excess resin was removed. All thecomposite specimens were dried at room temperature for 3 to 4 hours and cut into the size of $300 \times 300 \mathrm{~mm}$. In total, five composite specimens were prepared, as shown in Figure 1.
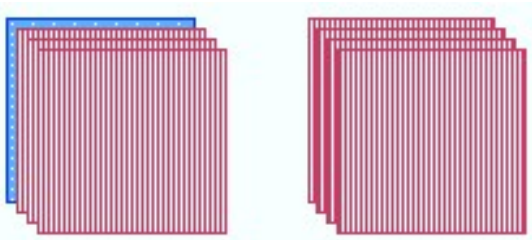

(D)

(E)

Fig. 1 Fabricated discarded fishnet of mesh size $32 \mathrm{~mm}$ at stretched orientation. $(\mathrm{A})=4 \mathrm{GF}$, $(\mathrm{B})=3 \mathrm{GF} / 1 \mathrm{FN},(\mathrm{C})=2 \mathrm{GF} / 2 \mathrm{FN}(\mathrm{D})=1 \mathrm{GF} / 3 \mathrm{FN}$ and $(\mathrm{E})=4 \mathrm{FN}(4 \mathrm{GF}=4$ glass fibre layers, $3 \mathrm{GF} / 1 \mathrm{FN}=3$ glass fibre and 1 fishnet layer, $2 \mathrm{GF} / 2 \mathrm{FN}=2$ glass fibre and 2 fishnet layers, $1 \mathrm{GF} / 3 \mathrm{FN}=1$ glass fibre and 3 fishnet layers and $4 F N=4$ fishnet layers) 


\subsection{Preparation of Hybrid Composites}

Tensile testing of the composites was measured according to the ASTM D-638 by using electronic tensile testing machine UTM TUE-CN-400 (Sl. No: 2014/136, Fine Spray Associates and Engineers, India) instrument at $28{ }^{\circ} \mathrm{C}$ with $40 \pm 2 \%$ relative humidity, crosshead speed of $5 \mathrm{~mm} / \mathrm{min}$ and a gauge length of 100 $\mathrm{mm}$. The tensile modulus and elongation at the break of the composites were calculated from the loaddisplacement curve. Five specimens were tested for each set of samples, and the mean values were obtained.

\subsection{Scanning Electron Microscope (SEM)}

The surface morphology of the hybrid composites was examined using a scanning electron microscope (Model: SEG100). The samples were mounted onto SEM holders using double-sided electrically conducting carbon adhesive tapes to prevent surface charge on the specimens when exposed to the electron beam. The microscopic images of the specimens after tensile tests were obtained from COSLAB (Model No: ZSM 116) compound light microscope with photo capturingsoftware.

\subsection{Dynamic Mechanical Analysis (DAM)}

Dynamic mechanical analysis Q800 V20.6 Build 24, USA was used to evaluate loss modulus, storage modulus and mechanical damping $(\tan \delta)$. The heating rate was used at $2{ }^{\circ} \mathrm{C} / \mathrm{min}$ and frequency at $1 \mathrm{~Hz}$ under amplitude control. Liquid nitrogen was used as a cooling agent, and the temperature ranges from $28^{\circ} \mathrm{C}$ to $200{ }^{\circ} \mathrm{C}$. The sample thickness is $2.5-3 \mathrm{~mm}$, width $9-10$ $\mathrm{mm}$, and 50-60 $\mathrm{mm}$.

\section{Results and Discussion}

\subsection{Tensile Properties}

The tensile behaviours of glass fibre and discarded multifilament fishnet hybrid composites are indicated in Table 1. The tensile strength of glass fibre composite $4 \mathrm{GF}$ is $86.7768 \mathrm{MPa}$, and discarded fishnet fibre composite $4 \mathrm{FN}$ is $87.1771 \mathrm{MPa}$. When glass fibre is replaced by discardedmultifilament fishnet fibre in the composites, $3 \mathrm{GF} / 1 \mathrm{FN}, 2 \mathrm{GF} / 2 \mathrm{FN}$, and $1 \mathrm{GF} / 3 \mathrm{FN}$ have the tensile strength values $86.8752 \mathrm{MPa}, 86.9764 \mathrm{MPa}$ and $87.0760 \mathrm{MPa}$, respectively.

Table 1 Effect of fishnet fibre loading on glass fibre of tensile properties of different composites

\begin{tabular}{ccccc}
\hline Composites & $\begin{array}{c}\text { Tensile strength } \\
{[\mathrm{MPa}]}\end{array}$ & $\begin{array}{c}\text { Standard } \\
\text { deviation }\end{array}$ & $\begin{array}{c}\text { Tensile modulus } \\
{[\mathrm{GPa}]}\end{array}$ & $\begin{array}{c}\text { Standard } \\
\text { deviation }\end{array}$ \\
\hline $4 \mathrm{GF}$ & 86.7768 & 1.4034 & 11.5331 & 1.1021 \\
$3 \mathrm{GF} / 1 \mathrm{FN}$ & 86.8752 & 1.5462 & 11.5690 & 1.9562 \\
$2 \mathrm{GF} / 2 \mathrm{FN}$ & 86.9764 & 1.3546 & 11.6052 & 1.8243 \\
$1 \mathrm{GF} / 3 \mathrm{FN}$ & 87.0760 & 1.9564 & 11.6414 & 1.82546 \\
$4 \mathrm{FN}$ & 87.1771 & 2.1262 & 11.6771 & 1.9043 \\
\hline
\end{tabular}

Figure 2 depicted that when fishnet fibres replace the glass fibre in the composites, the tensile values are increased proportionally. Therefore, it is evident that the discarded multifilament fishnet composite $4 \mathrm{FN}$ has higher tensile strength than other fishnet incorporated composites and glass fibre composite. However, the interfacial adhesion of fishnet incorporated composites are comparable to the conventional glass fibre composite because multifilament twins have more threads woven together, which helps to bond well with the matrix. 
Journal of Manufacturing Engineering, June 2021, Vol. 16, Issue. 2, pp 051-060

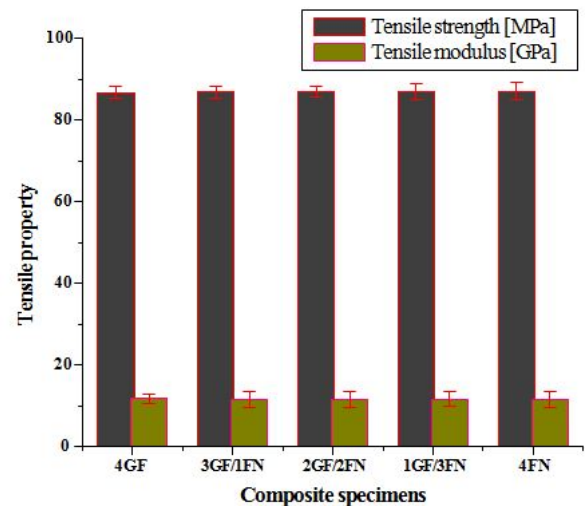

The micrographic images of the glass fibre and discarded fishnet composite specimens are subjected to tensile examination. It is found that bonding strength is better than the glass fibre composite, as shown in Figure 3. Hence the tensile yield of the fishnet based composite specimen 4FN is moderate because the inherent property of fishnet fibre alone is evident from Table 2

Fig. 2 Tensile behaviours of glass fibre and fishnet fibre composites

Table 2 The properties of glass fibre, fishnet fibre and polyester

\begin{tabular}{cccc}
\hline Properties & Glass fibre & Fishnet fibre & Polyester \\
\hline Density, g/cm ${ }^{3}$ & 2.5 & 1.15 & 1.14 \\
Elongation at break, \% & 4.8 & $15-45$ & $0.8-1.1$ \\
Young modulus, GPa & $70-73$ & $2-4$ & 18 \\
Tensile strength, MPa & $2000-3400$ & 415.7 & 18 \\
\hline
\end{tabular}
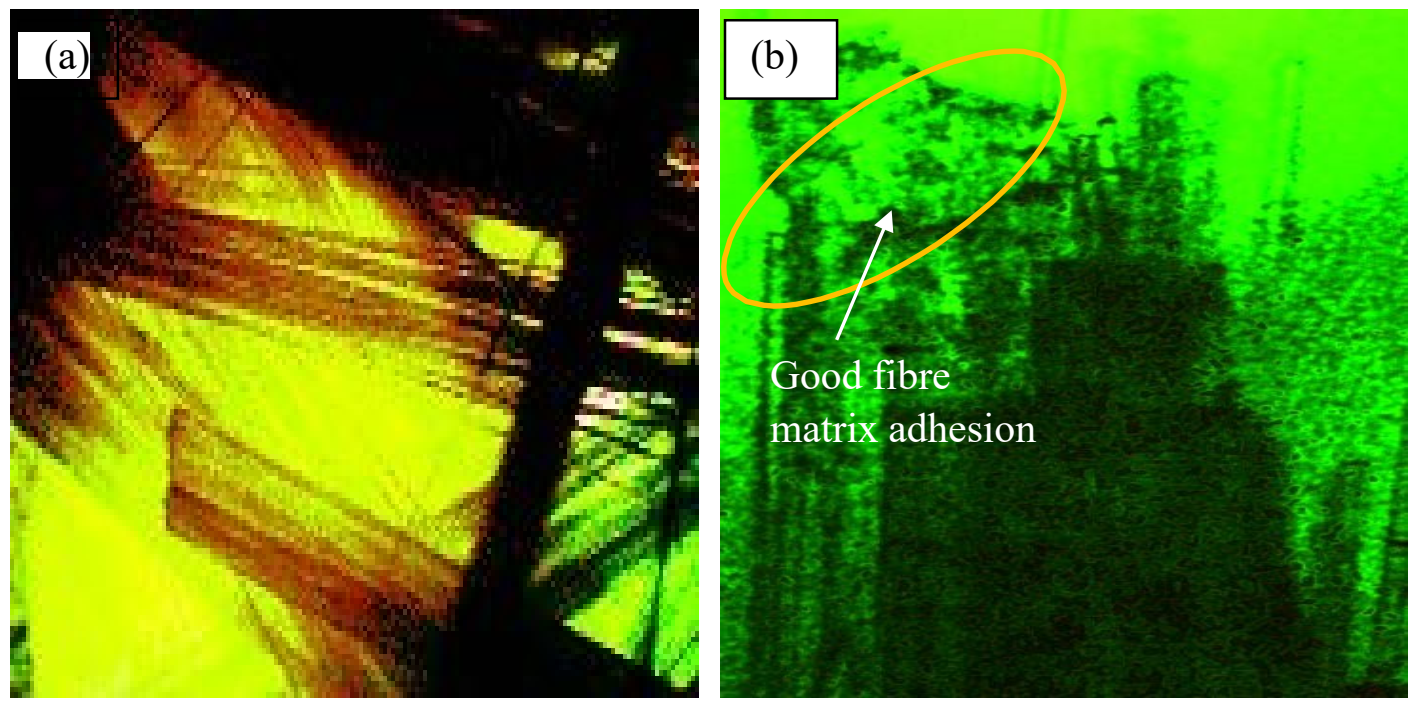

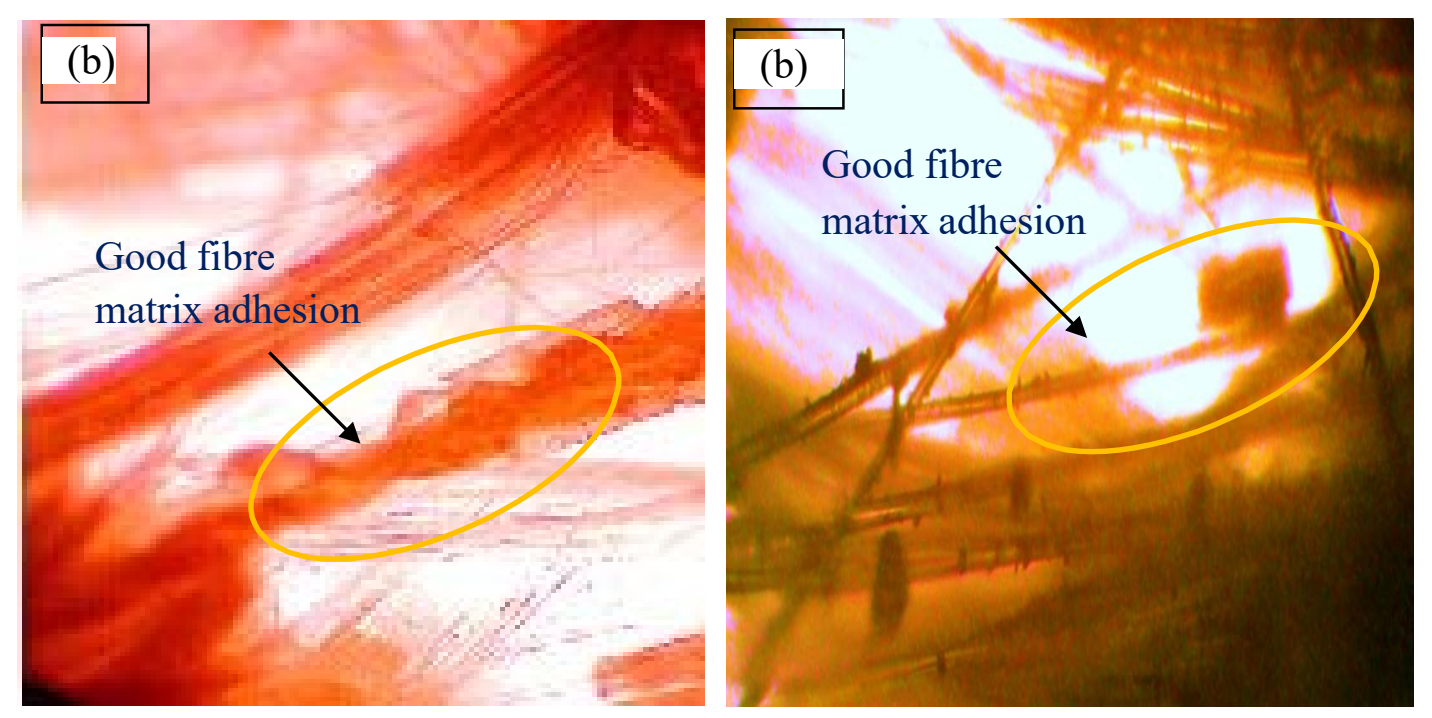

Figure 3. Micrograph images of glass fibre and discarded fishnet composites after the tensile break. (a) Glass fibre composite (b) Glass fibre and discarded fishnet composites.

The tensile modulus of glass fibre composite 4GF is $11.5331 \mathrm{GPa}$, and fishnet fibre-based composite $4 \mathrm{FN}$ is $11.6771 \mathrm{GPa}$. The tensile modulus of composite 4GF has more or less similar values compared with fishnet incorporated composites $3 \mathrm{GF} / 1 \mathrm{FN}, 2 \mathrm{GF} / 2 \mathrm{FN}$, $1 \mathrm{GF} / 3 \mathrm{FN}$ and $4 \mathrm{FN}$. When glass fibre layers are replaced with fishnet layers, the tensile modulus is found to be increased. The tensile properties of discarded fishnet composites have higher values when the fishnet layers are increased in the composites. Therefore, the multifilament discarded fishnet at stretched orientation plays a vital role as it increases the tensile strength and modulus because a large quantity of reinforcement was added to the composites.

\subsection{Scanning Electron Microscope (SEM)}

SEM examinations revealed that the composite specimens have good fibre matrix adhesion. From figure 4 (a) and (b), it is clear that the images indicated have no crack/fracture on the surfaces of the composite specimens. Figure 4 (b) indicates the good interfacial bonding between the discarded fishnet and the polyester resin matrix. The reinforcements of glass fibre and discarded fishnet are in polar nature, chemically with partial positive and negative ends. The polyester resin matrix material is also polar, and therefore, interaction with opposite charges of the matrix and reinforcements occur, which helps to have better interfacial bonding behaviour. This adhesion of the fibre and the polyester resin matrix is through hydrogen bonding, dipole interactions and Vander Walls forces of attraction. However, the entire study of SEM images reveals some roughness seen on the surfaces; this is due to the prevalence of some air sockets because of the hand layup technique. Discarded fishnet composites have low density when compared to glass fibre composites. Hence, it is considered as a filler material in the manufacturing of lightweight composites with high strength. Also, the cylindrical shape of the discarded fishnet fibre improves the bonding behaviour of the composites. 
Journal of Manufacturing Engineering, June 2021, Vol. 16, Issue. 2, pp 051-060
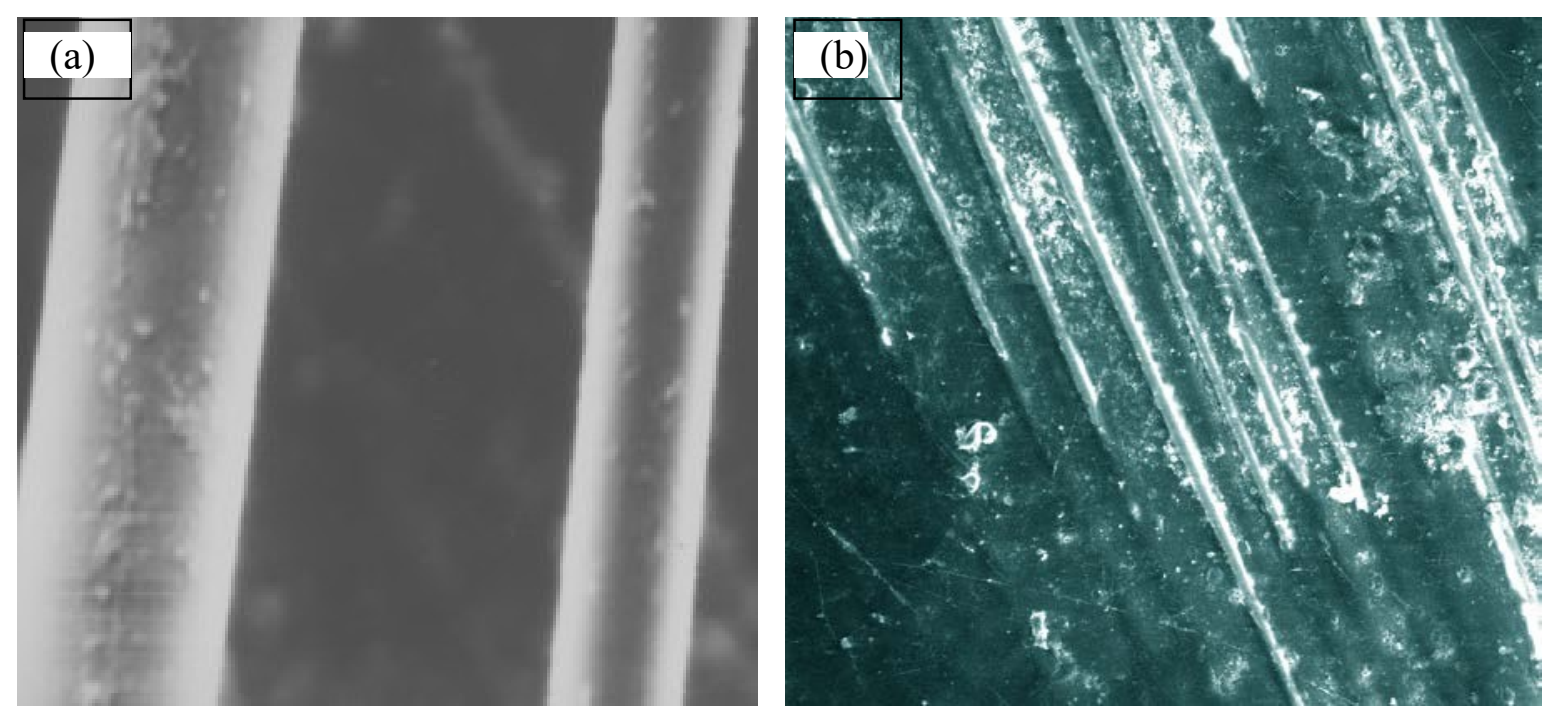

Figure. 4. (a) The glass fibre composite (b) The fishnet fibre-based composite

\subsection{Dynamic Mechanical Analysis (DMA)}

\section{Storage Modulus (E')}

The discarded fishnet and glass fibre results incorporated composites on the changes in storage modulus $\left(E^{\prime}\right)$ at a frequency of $1 \mathrm{~Hz}$. Storage modulus is defined as the energy stored in the elastic portion of the composites. The storage modulus $\left(E^{\prime}\right)$ for the composite $4 \mathrm{GF}$ is $4947 \mathrm{MPa}$ followed by fishnet substituted composites $3 \mathrm{GF} / 1 \mathrm{FN}, 2 \mathrm{GF} / 2 \mathrm{FN}$, and $1 \mathrm{GF} / 3 \mathrm{FN}$ have $4254.79 \mathrm{MPa}, 3375.896 \mathrm{MPa}$ and $2477.89 \mathrm{MPa}$ respectively at low temperature i.e. in the plastic region. The temperature is increased to the glassy region to decrease the storage modulus progressively. The storage modulus of fishnet fibre reinforced composite $4 \mathrm{FN}$ is $1343 \mathrm{MPa}$, whereas discarded fishnet is substituted as glass fibre composite $3 \mathrm{GF} / 1 \mathrm{FN}$ compared to glass fibre composite $4 \mathrm{GF}$ as shown in figure 5. However, the storage modulus of discarded fishnet fibre andglass fibre incorporated composite $3 \mathrm{GF} / 1 \mathrm{FN}$ has a value very close to that of composite $4 \mathrm{GF}$.

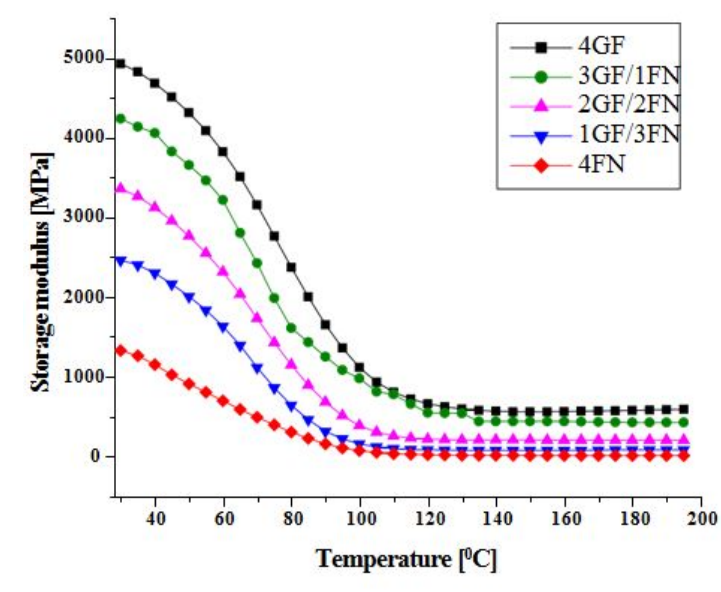

Figure 5. Plots of storage modulus, $E^{\prime}$, vs temperature, ${ }^{\circ} \mathrm{C}$, for relevant composite specimens

The glass fibre composite is found to be more effective reinforcement than fishnet composites. The efficiency of glass fibre composites is marginally higher due to the orientation offibres. It is found that the fishnet fibre reinforcement decreases with the addition of fishnet in the place of glass fibre. Hence, $E^{\prime}$ values of adequate reinforcements are comparatively identical, suggesting that fishnet can be a good substitute for glass fibre. Therefore, the alternatematerial of fishnet fibre and glass fibre has induced excellent stress transfer and matrix adhesion. 


\section{Loss Modulus (E”)}

The viscous response of the composites concerning temperature is called the loss modulus. The deviation of the loss modulus $\left(E^{\prime \prime}\right)$ of glass fibre and fishnet fibre reinforced composites is a function of temperature at a frequency of $1 \mathrm{~Hz}$. However, $E^{\prime \prime}$ is governed by the molecular motions within the composite materials. The loss modulus values depend upon the type and the number of reinforcements. In figure 6 it indicates that loss modulus increases up to a specific temperature and then decreases. However, the values of $E^{\prime \prime}$ are found to vary much for different composites, which indicates different $\mathrm{Tg}$ values. The $E^{\prime \prime}$ curves of fishnet incorporated composites broaden depending on the number of layers; specimen 4GF has a curve that has the maximum broadening effect. The broadening is due to the difference in the physical state of the matrix surrounding the reinforcing fibres. Loss modulus is maximum for $4 \mathrm{GF}$, whose $\mathrm{Tg}$ value is $86.029{ }^{\circ} \mathrm{C}$, and fishnet incorporated composite $3 \mathrm{GF} / 1 \mathrm{FN}$ has comparable $\mathrm{Tg}$ value. Therefore, the low $\mathrm{Tg}$ value of the fishnet composite reflects comparatively lesser interaction of the discarded fishnet with matrix than glass fibre.

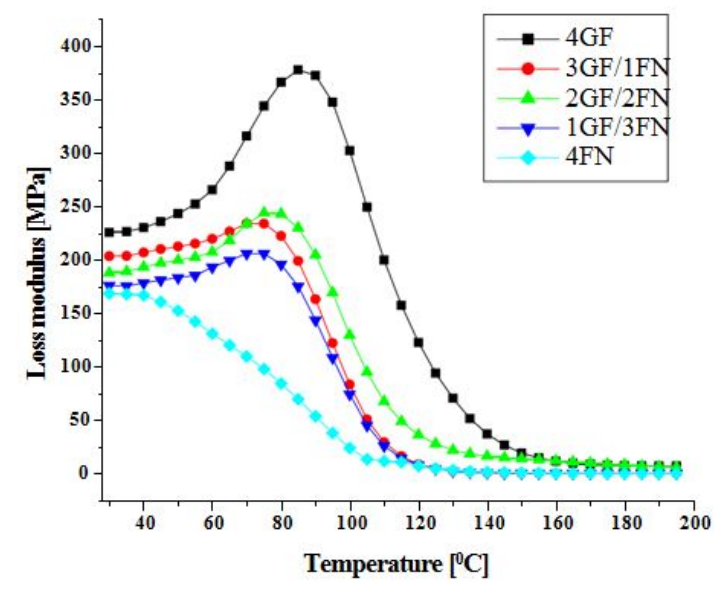

Figure 6. Plots of loss modulus, $E^{\prime \prime}$, vs. temperature, ${ }^{\circ} \mathrm{C}$, for relevant composite specimens

The value of change in loss modulus follows the same trend as that of $\mathrm{Tg}$ of composites $4 \mathrm{GF}$ and $3 \mathrm{GF} / 1 \mathrm{FN}$ as shown in table 3 . It is attributed to the improved rigidity of the composites resulting from more vital interface interaction with the reinforcement and matrix. It is evident that composite $4 \mathrm{GF}$ is better than fishnet based composite 4FN from figure 6. Therefore, the variation in loss modulus values of composites $4 \mathrm{GFand} 3 \mathrm{GF} / 1 \mathrm{FN}$ is very minimum.

Table 3 DMA values achieved from various composites

\begin{tabular}{cccc}
\hline $\begin{array}{c}\text { Composite } \\
\text { specimens }\end{array}$ & $\begin{array}{c}\text { Tg from E" } \\
\text { curve 0C }\end{array}$ & $\begin{array}{c}\text { Tg from } \tan \delta \\
\text { curve 0C }\end{array}$ & $\begin{array}{c}\text { Peak height of } \\
\tan \delta \text { curve }\end{array}$ \\
\hline 4GF & 86.029 & 102.837 & 0.26939 \\
3GF/1FN & 74.969 & 102.037 & 0.28478 \\
2GF/2FN & 72.498 & 99.234 & 0.30428 \\
$1 \mathrm{GF} / 3 \mathrm{FN}$ & 70.205 & 98.423 & 0.34789 \\
$4 \mathrm{FN}$ & 50.831 & 97.434 & 0.40972 \\
\hline
\end{tabular}

\section{Damping factor $(\tan \delta)$}

The quantum of fibre and matrix adhesion depends on the values of mechanical damping $(\tan \delta)$.
The damping behaviour of the composites is the ratio between the loss modulus and storage modulus. However, the damping performance will affect the composites having the incorporation of fibre in the matrix adhesion. The variation of $\tan \delta$ is due to stress concentrations in the fibres and viscoelastic energy dissipation in the polyester matrix. As a result, the 
weaker fibre matrix bonding will result in higher values of damping ( $\tan \delta$ ). However, good fibre matrix bonding of the composites induced mobility of the polymer chains to reduce mechanical damping. Therefore, the low $\tan \delta$ value shows that specific composite material has a good load-bearing capacity, as shown in Figure 7. Mechanical damping is very high for fishnet based composites, while it is low for glass fibre composite. The $\tan \delta$ values of glass fibre and fishnet hybrid composites $4 \mathrm{GF}$ and $3 \mathrm{GF} / 1 \mathrm{FN}$ have very small variations.

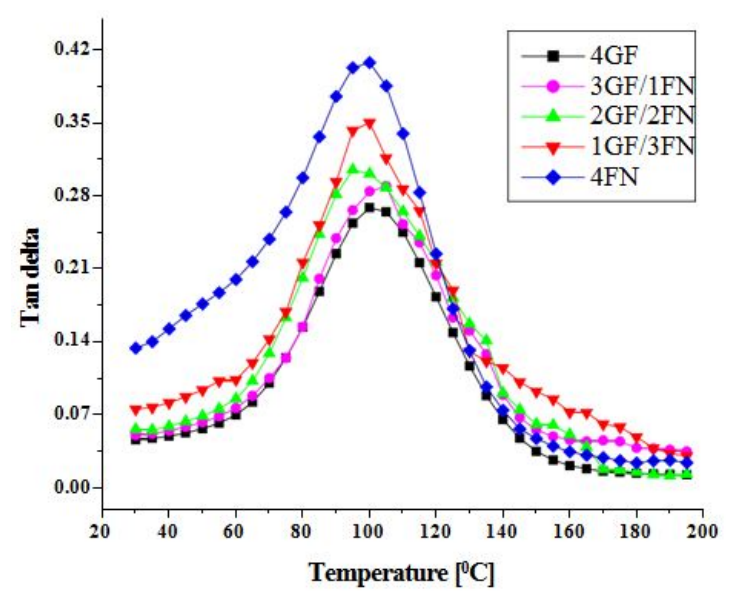

Figure 7. Plots of tan d vs. temperature, ${ }^{\circ} \mathrm{C}$, for relevant composite specimens

\section{Cole-cole plot}

Cole-Cole diagram plots the loss modulus $\left(E^{\prime \prime}\right)$ as a function of storage modulus $\left(E^{\prime}\right)$ for the glass fibre composite and fishnet fibre composites. It is reported that a semicircle plot represents the homogeneity of the composites. It is obvious from Figure 8 that $3 \mathrm{GF} / 1 \mathrm{FN}$ and $2 \mathrm{GF} / 2 \mathrm{FN}$ composite forms an almost perfect semicircle indicating the homogeneity of the composites. Composites made up of glass fibre also have similar characteristics. However, when fishnet is completely substituted for glass fibre, the homogeneity is decreased, and the plot has an imperfect semicircle. Imperfect semicircles correspond to composites of a heterogeneity nature. This characteristic is observed clearly in the case of fishnet composite only.

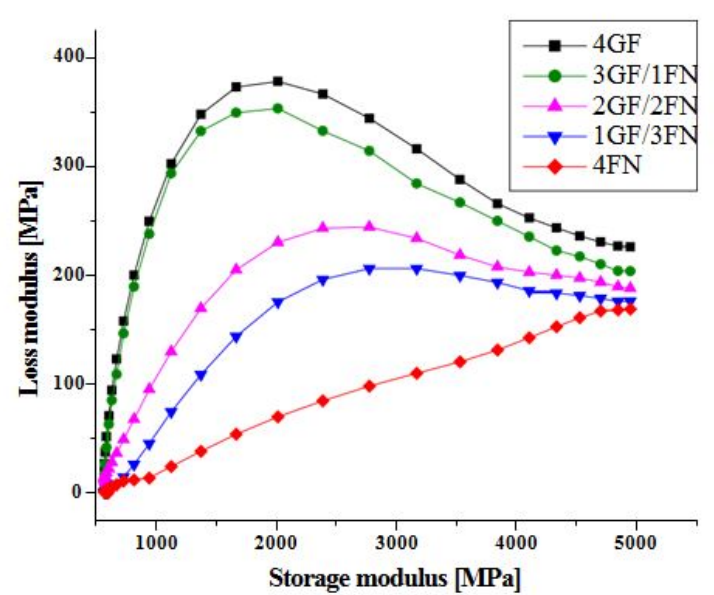

Figure 8. Plots of storage modulus vs. loss modulus for relevant composite specimens

\section{Glass Transition Temperature ( $\mathrm{Tg})$}

Glass transition temperatures of the composites $4 \mathrm{GF}, 3 \mathrm{GF} / 1 \mathrm{FN}, 2 \mathrm{GF} / 2 \mathrm{FN}, 1 \mathrm{GF} / 3 \mathrm{FN}$ and $4 \mathrm{FN}$, was evaluated from the E', E" and tan $\delta$ curves (see Figs. 6, 7 and 8) are summarized in Fig. 9. The composite specimen $4 \mathrm{GF}$ of glass transition at a $\tan \delta$ peak temperature and the glass transition temperature of E" was appeared as the highest values. Composite $4 \mathrm{FN}$ has the low glass transition temperature of at $\tan \delta$ peak temperature and $\mathrm{Tg}$ of E". The composite $3 \mathrm{GF} / 1 \mathrm{FN}$ were found the $\mathrm{Tg}$ value $102.037{ }^{\circ} \mathrm{C}$ at $\tan \delta$ peak temperature and $\mathrm{Tg}$ of $74.969{ }^{\circ} \mathrm{C}$ at E". The Tg value of composite 4GF was found to be $86.029{ }^{\circ} \mathrm{C}$ has marginally higher than the $\mathrm{Tg}$ of the composite 3GF/1FN. The Tg measured by using DMA analysis traces significantly different for the composites $4 \mathrm{GF}$ and $3 \mathrm{GF} / 1 \mathrm{FN}$. It has been recommended by some researchers that GFRP should have a glass transition temperature that is at least $30{ }^{\circ} \mathrm{C}$ higher than the maximum expected temperature during its service life [23]. 
Journal of Manufacturing Engineering, June 2021, Vol. 16, Issue. 2, pp 051-060

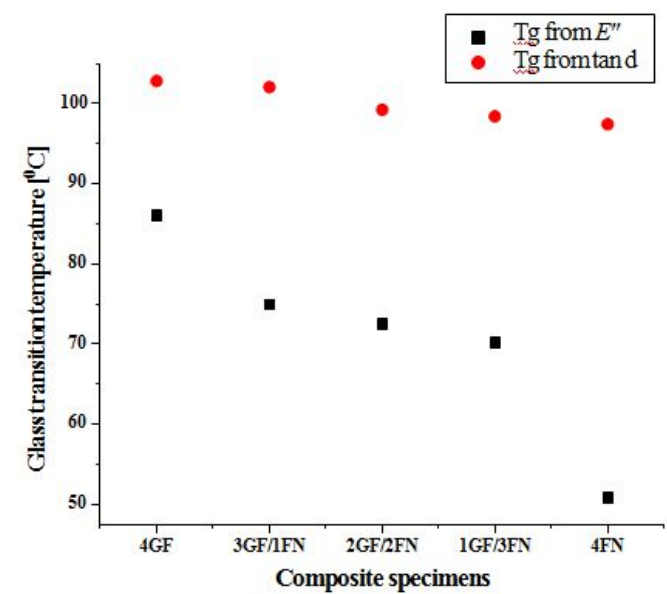

Fig. 9 Comparative glass transition temperatures of various composite specimens

\section{Conclusions}

Study of novel hybrid composites of discarded multifilament fishnets of mesh size $32 \mathrm{~mm}$ was substituted for glass fibre with polyester matrix, tensile and dynamic mechanical properties were evaluated, and the conclusions are given below.

i. The addition of fishnet layers into the composites increases proportionally to the tensile strength and tensile modulus because it has more fishnet material per unit area of the composites. The micrograph images of the specimens subjected to tensile test were observed from the adhesion of the glass and fishnet fibres along with matrix is good.

ii. Scanning Electron Microscopy images of glass fibre and discarded fishnet composites revealed that the fishnet incorporated composites have good interfacial bonding between fibre and matrix.

iii. The storage modulus of discarded multifilament fishnet composite $3 \mathrm{GF} / 1 \mathrm{FN}$ has a considerable value of glass fibre composite 4GF. The Tg value of loss modulus is maximum for glass fibre composite than others; this reflects the rigidity of the composite. However, the loss modulus of glass fibre and fishnet fibre incorporated composites $3 \mathrm{GF} / 1 \mathrm{FN}$ do not lag far behind.

iv. Damping values of composite $4 \mathrm{GF}$ has been compared to the composite $3 \mathrm{GF} / 1 \mathrm{FN}$. The Tg value of composite $4 \mathrm{GF}$ is higher than other composites. Cole-cole plot of the composites $3 \mathrm{GF} / 1 \mathrm{FN}$ and $2 \mathrm{GF} / 2 \mathrm{FN}$ has formed about perfect semicircle representing the homogeneity.
Therefore, partially substituted fishnet-glass fibre composites can serve as an alternate and a low-cost hybrid composite. The utilization of discarded multifilament fishnet in the manufacturing of composites also helps with waste disposal and minimises environmental impacts.

\section{References}

1. Ku H, Wang H, Pattarahaiyakoop N, Trada M. A review of tensile properties of natural fibre reinforced polymer composites. Composites: Part B 2011; 42(4): 856-73.

2. John MJ, Sabu T. Biofibres and Biocomposites. Carbohydr Polym 2008; 71(3): 342-64.

3. Moe MT, Kin L. Characterization of bamboo-glass fibre reinforced polymer matrix hybrid composite. J Mater Sci Eng Lett 2000; 19: 1873-6.

4. Mishra S, Mohanthy AK, Drzal LT, Misra M, Parija S, Nayak SK. Studies on mechanical performance of biofibre/glass reinforced polyester hybrid composites. Compos Sci Technol2003; 63(10): 1377-85.

5. Athijayamani A, Thiruchitrambalam $M$, Natarajan $U$, Pazhanivel B. Effect of moisture absorbance on the mechanical properties of randomly oriented natural fibres/polyester hybrid composites. Mater Sci Eng A 2009; 517(1-2): $344-53$

6. Pothan LA, Zachariah O, Sabu T. Dynamic mechanical analysis of banana fibre reinforced polyester composites. Compos Sci Technol 2003; 63(2): 283-93.

7. Jose Jr HSA, Heritor Jr Lo, Sandro Ca, Franco Dra. Study of hybrid interlaminate curaua/glass composites. Mater Des 2012; $42: 111-7$

8. Idicula M, Malhothara SK, Joseph K, Thomas S. Dynamic mechanical analysis of randomlyoriented intimately mixed short banana/sisal hybrid fibre reinforced composites. Compos Sci Technol 2005; 65(7-8): 1077-87.

9. Jawaid M, Abdulkalil HPS, Azman H, Rudi D, Hadiyane A. Effect of jute fibre loading on the tensile and dynamic mechanical properties of oil palm epoxy composites. Composites: Part B 2013; 45(1): 619-24.

10. Ozturk bulent. Hybrid effect in the mechanical properties of jute/rockwool hybrid fibre reinforced phenol formaldehyde composites. Fibre Polym 2010; 11(3): 46473.

11. Gu $J$ Wu $G$, Zhang $O$. Preparation and damping properties of flyash filled epoxy composites. Mater Sci Eng A 2007; 452-453: 614-8.

12. Jacob M, Francis B, Thomas S, Varughese KT. Dynamical mechanical analysis of sisalloilpalm hybrid fibre-reinforced natural rubber composites. Polym Compos 2006; 27(6): $671-80$. 


\section{Journal of Manufacturing Engineering, June 2021, Vol. 16, Issue. 2, pp 051-060}

13. Pothan LA, George CN, John MJ, Thomas S. Dynamic mechanical and dielectric behavior of banana-glass hybrid fibre reinforced polyester composites. $J$ Reinforced Plast Compos 2010; 29(8): $1131-45$.

14. Ornaghi Jr HL, Bolner AS, Fiorio R, Zattera AJ, Amico $S C$. Mechanical and dynamic mechanical analysis of hybrid composites molded by resin transfer molding. J Appl Polym Sci 2010; 118(2): 887-96.

15. Michael raj $F$, Nagarajan VA, Vinod kumar KP. Evaluation of mechanical behavior of multifilament waste fishnet/glass fibre in polyester matrix for the application of mechanized boat deckhouse in marine composites. Applied Mechanics and Materials 2014;592-594: 2639-2644.

16. Michael raj F, Nagarajan VA, Vinod kumar KP. Mechanical behavior of FRP composites with used Fish net/glass fibre and polyester matrix. International Journal of Applied Engineering Research (IJAER) 2015; 10: 63756378 .

17. F. Michael Raj, K. P. Vinod Kumar, S. Sahaya Elsi, M. M. $G$ Jersy, , "Hybrid composites with discarded fishnet and polyester: a novel boat-building material" Ships and Offshore Structures, 2018 https://doi.org/10.1080/17445302.2018.1464890

18. Michael Raj.F, Nagarajan.V.A, S. Sahava Elsi, “Waste to Poles: Discarded fishnet/glass fibre and Polyester for Poles: Discarded fishnet/glass fibre and Polyester for
building Electrical Poles" Polymer Composites 2018, 29973005 .
19. A. Amala Mithin Minther Singh, F. Michael Raj, P. Arul Franco, J.S. Binoj, "Evaluation of mechanical behavior of multifilament discarded fishnet/glass fibre and polyester composites for marine applications" Marine Structures 2018, 58, 361-366.

20. Michael Raj F, V.A. Nagarajan and S. SahayaElsi, "Mechanical Characterization of Discarded Monofilament Fishnet/Glass Fibre and Polyester Hybrid Composites", Indian Journal of Ecology 2017, 44(2): 402-409.

21. Michael Raj.F, Nagarajan.V.A S. Sahaya Elsi, "Mechanical, physical and dynamical properties of glass fibre and waste fishnet hybrid composites" Polymer Bulletin 2016. DOI10.1007/s00289-016-1783-3

22. Michael Raj. F, V.A. Nagarajan, S. Sahaya Elsi, R.S. Jayaram, "Effect of fibre content onflexural properties of
fishnet/GFRP hybrid composites" Steel and Composite Structures, 2016, Vol. 22, No. 1, 13-24.

23. Guide for the design and construction of structural concrete reinforced with FRP bars. ACI440.1R-06, 2006. 